\title{
An Intelligent Framework of Oral Examination System under Network Environment and Its Application
}

\author{
Weifeng $\mathrm{MA}^{1}$ and Xiaoyong $\mathrm{SUN}^{2}$ \\ ${ }^{1}$ School of Information and Electronic Engineering, Zhejiang University of Science \\ and Technology, Hangzhou 310023, China \\ ${ }^{2}$ School of Sciences, Zhejiang University of Science and Technology \\ tomma@21cn.com,8819684@163.com
}

\begin{abstract}
As a crucial step in the process of teaching and training, examination, espectally oral examination, is characterized with such defects as excessive subjectivity, difficult organization, low efficiency and heavy pressure. Thus, network technology and computer technology are employed to further promote the informationization of traditional oral examination. Through analyzing the existing problems of traditional oral examination and the feasibility of oral examination under network environment, this paper puts forward a universal framework and management model for oxalCexamination under network environment and designed an oral examinofion system based on digital voice technology, artificial intelligence and software engineering. The research findings have been applied to mandarin Chinese test. So far Over 10 organization users have adopted the system and more than 300,000 examinees have been cested. Viewed from the practice, expected effects have been achieved.
\end{abstract}

Keywords: Oral examingmon, Network examination, CAI, Mandarin proficiency test

\section{Introduction}

Under the background of deepening the educational reform by "greatly improve the modernization of educational technology methods and the degree of educational informatization", "take effective measures and energetically develop outstanding educational teaching software" and so on, the computer application technology has infiltrating into the educational field constantly; especially with the rapid development of computer network, the computer application technique is widely used in educational field as a modern means of education [1]. As an important part in the teaching process---the computer-based test has attracted more and more attention. The traditional exams need to go through many steps from setting a paper, printing papers; organizing examination rooms to correcting papers which is a long exam cycle with poor efficiency, also the fairness of exams might be affected. The conputer assisted examination system is an important link in the computer assisted instruction. It comparatively reduces the influence of human subjective factors in each steps of the exam, organizes the exam in faster, more objective and more safety way, and plays a significant role in improving teaching quality and efficiency. At present, the computer examination system has been widely used in various exams, such as computer exam of a course, computer rank examination, and various certification exams and so on. Therefore, the oral examinations with certain particularities will also face an information-based reform. From the perspective of theoretical analysis, Zhanglei from Faculty of Education, The 
Chinese University of Hong Kong had made feasibility experiment and theoretical study on the recording based mandarin proficiency test in 2000, the findings showed that the test results of recording scores are in correspondence with live scores, at least $90 \%$ of the capacity variance can be differentiated [3]; from the perspective of technical implementation, some researchers have made lots of profitable attempt on the development of oral English examination system $[4,5]$. The basis and results of those research works have provided as a reference to the further information-based reform of oral examinations.

\section{The Problems Existing in Traditional Oral Examinations}

The oral examination, such as the test of Chinese as a foreign language, the national mandarin proficiency test, foreign language oral test and so on, is part of the language examinations, which need to differentiate between the examinee's pronunciation and a certain standard by listening;. Different from other exam types, the traditional oral test has its own characteristics and also some problems:

\section{(A) The Problems Caused by the Face-to-face Test and Gradîng}

(1) The subjective factors are serious; the human relationship cannot be avoided;

(2) The grading standard is difficult to be unified due to the individual differences of scorers; even the person himself is difficult to keep a complete consistency of his standard from the beginning to the end;

(3) The test is inefficient and difficult in organization; when there are too many examinees, the workload of the examination would be very heavy, such as the final exam of oral English, basically each teacher has to spend 1-2 workdays tofinishit;

(4) Since it is the face to face exam, a quite big psychological impact on examinees may affect the exam results.

\section{(B) The Save Method to the Traditional Test Contents and Results is Fall Behind}

Oral test is different fromother tests thatcan save the test contents and results by papers, but to record the voice stream based real-time and dynamic tests as well as the grading process through tapes For the traditional pattern, those tapes are just the carriers for keeping and are difficult to nake further use, such as it can't be used to do further teaching information processing and analyzing to get the first-hand teaching information, which could be fed back in teaching activities.

Based on the consideration of the above problems, the paper is not only to study on applying the compater application technology such as digital record, artificial intelligence recognition and differentiation to the oral examinations, but to study the standardized management of the examine process from the management point of view, dynamically combines people with computer, maximizes the efficiency of the computer assisted examination system, to solve the above problems effectively.

\section{The Computer Assisted Oral Examinations and Management Model}

Examination is a check to the students' learning progress in teaching process; it is neither an isolated unit, nor the end of the teaching process, but a very important constituent of the teaching process, the two are intrinsically linked together. Therefore, the exam informatization is not only to design and develop a kind of software with the function of examinations, but to seamlessly integrate the exam system into the course of teaching for the improvement of teaching. At present, most of the computer assisted examinations systems, which are unable to achieve the teaching effects at last, are just simply providing a sort of 
network examination software, and have ignored the internal relations between examination and teaching.

A superior computer assisted examination system should have output which is capable of processing and analyzing the teaching information, feeding back to the teaching process, forming a favorable positive feedback loop, standardizing the process management, and fully integrating the people, systems and resources. Therefore, in the information-based reform of oral examination, we make an in-depth insight and analysis to various process sections of oral teaching, exam and management, and bring forward a reasonable model of computer assisted oral test and management, see Figure 1.

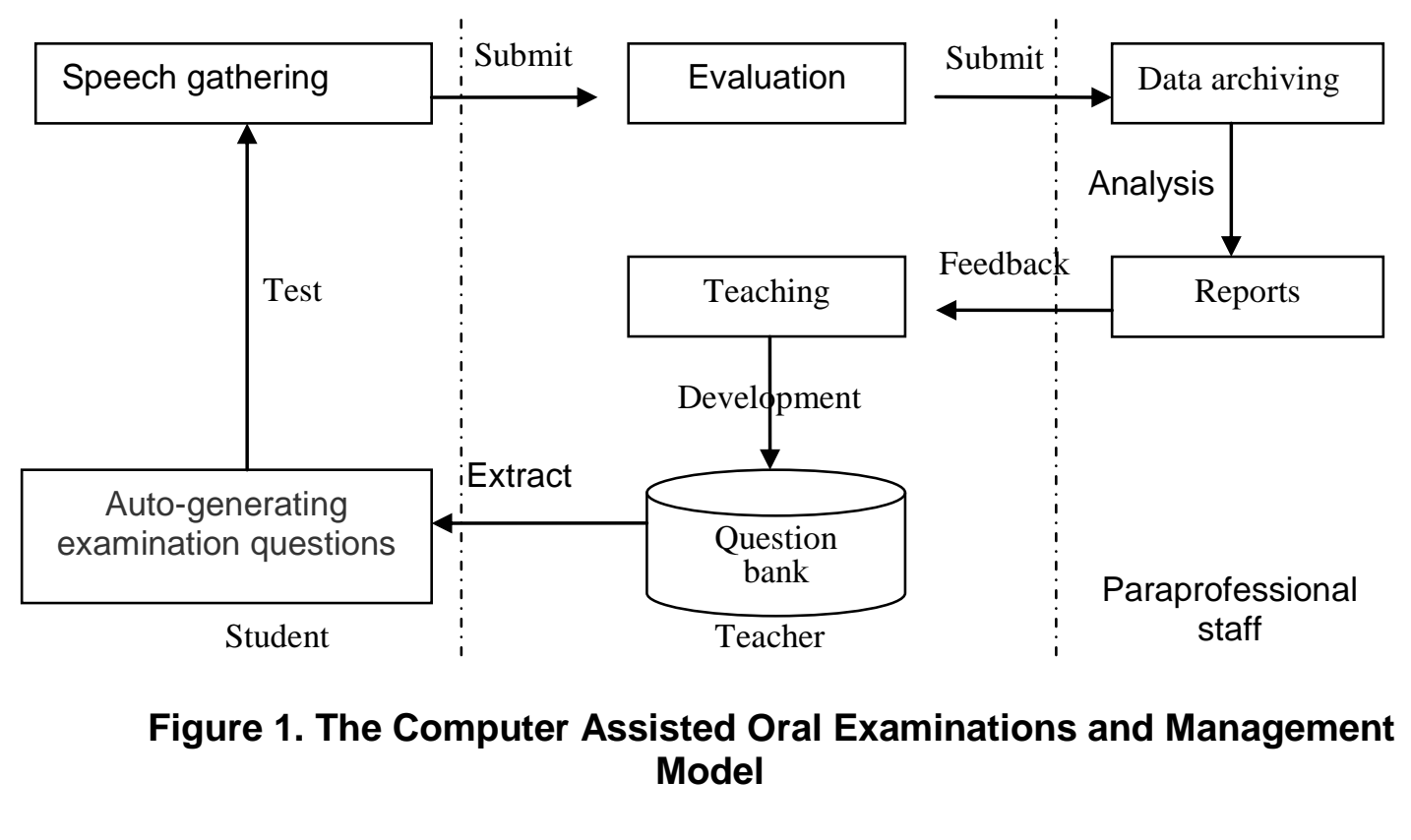

Analyze on Figure 1 the teachers teaching is the center of the entire mode, and tightly focusing on the ultimate goal of promoting the teaching is the mode designing aim. The teachers and students are the main participants of the teaching and learning activities, and finally examinations are used to measure the students' mastery of knowledge. Firstly, with the support of computer assisted system, teachers design and develop the examination database based on the instructionalcontents and objectives. After the teaching course is finished, teachers just need to secthe test contents and difficulties, timely organize students to have an exam. In the examination, the papers are formed by the system which can extract relevant exam questions from the examination database automatically. The exam procedure is a digital acquisition process of students' speech. Afterwards, the system retrieves the collected speech materials; teachers will score the examinations according to their own timetable, and submit both of the results and speech materials for filing. At last, paraprofessional staff will archive the scoring results and speech materials reasonably, make use of the computer assisted system to do related statistics and teaching information processing and analysis, and submit teaching feedback report to the corresponding classroom teachers. The teachers will adjust the teaching contents properly according to the feedback, thus the whole process has formed a closed positive feedback loop.

In the entire mode, the three types of people involved have clear-cut assignments and independent responsibilities which specify the overall management process of the examination. Meanwhile, it adapts the advanced computer application technology in the whole exam process which will support each type of staff in a better way, reduce the working 
pressure, enhance the efficiency, make the exam more objective and more fair, and further promote the teaching.

\section{The General Framework and Core Technology of Oral Examination System}

Under the theoretical guidance of oral examinations and management models, we bring forward a general framework of computer assisted examination system, which is fit for all kinds of oral examinations, based on the actual application requirements of foreign language oral exams, Chinese as a second language exam, mandarin proficiency test and so on. See Figure 2.

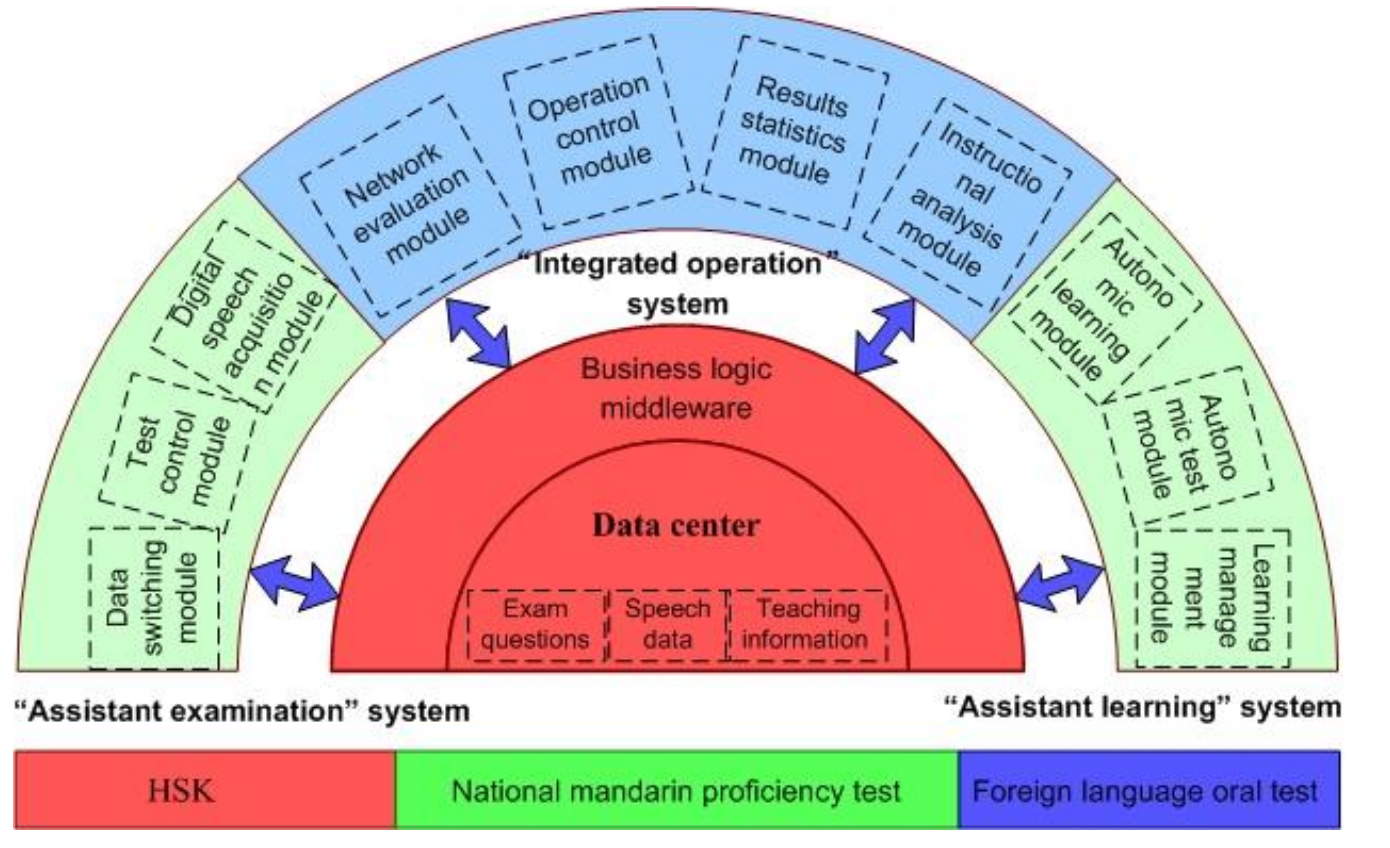

Figure 2. The Proposed System Framework

As shown in Figure 2, the proposed system framework is consist of three subsystems which are "assistant examination" system, "assistant learning" system and integrated operation system, as we11 as one data center, namely " $3+1$ " model. The business logic of the three subsystems can be achieved by adopting middleware technology, communicate with data center server through LAN (local area network) or WAN (wide area network). While the exam questions data, the collected speech data, teaching information processing and results data analyzing, the examinees' basic information and so on are all storage in the data center.

\subsection{Assistant Examination" System}

The "assistant examination" system mainly caters to the examinees, which is composed of digital speech acquisition module, test control module and data switching module. The test control module is to support the examination organizers to collect and manage the examinees' basic information, provide the configuration of the exam questions, as well as the exam site monitoring and so on; the digital speech acquisition module is mainly to make digital recording during the exam process, which can be done by computer sound card or professional multichannel voice card; data switching module is use to submit or synchronize 
data to the data center server, the data includes the exam questions data, the examinees' basic information, the exam site situation, the collected speech data and so on.

\subsection{Integrated Operation System}

The integrated operation system is used mainly to control and maintain the operation of the exam process, including network evaluation module, operation control module, results statistics module and instructional analysis module. The network evaluation module provides a kind of remote scoring way, which is to evaluate the exam records saved in data center and submit the results; the operation control module provides the control to the exam questions and the evaluation staff information, offers evaluation job assignment, evaluation real-time monitoring and so on. The results statistics module is to count, audit and issue the results; the instructional analysis module generates exam feedback report and instructional feedback report automatically by way of substantial statistics and instructional information processing.

\section{3 "Assistant learning" System}

The "assistant learning" system includes autonomic learning module, autonomic test module and learning management module. In the autonomic learning module, examinees can feedback report according to their own learning situation and examination, and study independently by the assistant system; the autonomic lest module is a simplified "assistant examination" system, examinees can collect speech by modeltest, and listen repeatedly or upload to the data center for being evaluated by teacher; the learning management module is to monitor and record the process of the examynation for the promotion of learning.

At present, the database technique (such as SQI Server, Oracle and DB2, etc.,), speech technology and J2EE program development technique are all mature, these key techniques ensure the implementation of the general purpose system effectively.

\section{Application Research}

National mandarin test is a test system designed for speeding up the process of mandarin popularization and improving the mandarin level of the whole society. With practical research work, we applied the model and system framework to the informationalization reform of national mandarin test in zheggjang province and reached certain achievements.

\subsection{The Situation and Problems Analysis in Mandarin Test}

Traditional mandarin test by face to face has some disadvantages, such as difficulty and high cost of organization, more human factors and difficulty in management, especially the large-scale lesting. For those problems and difficulties, almost all the centers in different provinces have started to explore the informationalization to some extend, some provinces, such as hy nan, tian jin, shang hai, zhengjiang, have started even earlier to apply information technology to testing. At present, the organization and application work of mandarin test in Zhejiang province is in charge of each testing spot, the organization structure is shown in Figure 3: 


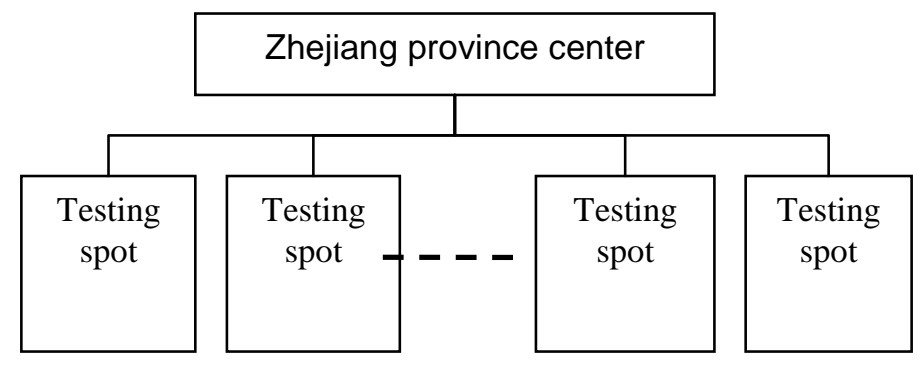

\section{Figure 3. The Organization of Mandarin Test in Zhejiang Province}

\subsection{The Realization of Mandarin Test System based on the Combination of $B / S$ and $C / \vec{S}$}

Basing on the wide survey about the needs of potential system users and common system framework of oral testing, we divide the system into 3 subsystems according to functions and actual working process, which are drawing lots on site and testing subsysten, network-based grading subsystem and network-based management of testing process subsystem, as shown in Figure 4.

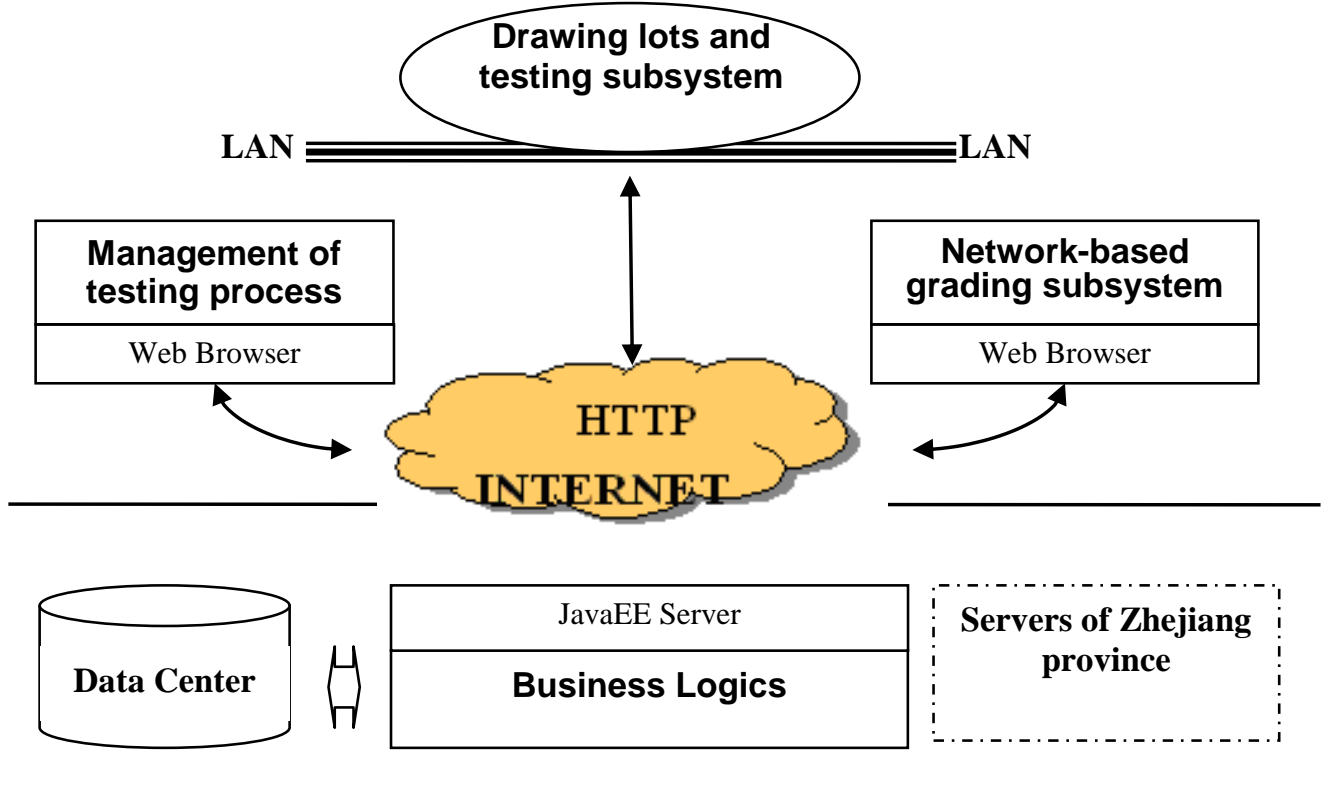

Figure 4. The Mandarin Test System based on the Combination of B/S and C/S

Drawing lots on site and testing subsystem is based on the C/S structure and uses Delphi + SQL SERVER technology. This subsystem is equipped in computer room or specific language lab of each testing spot. It's mainly for the functions such as candidates' information management, test questions configuration, oral material collection, etc.,.

Network-based grading subsystem is based on B/S structure and uses Activex and streaming media component. It's equipped on the server of each provincial center and applied for remote grading on internet by tester.

Network-based management of testing process subsystem is based on B/S structure of JavaEE platform. It's equipped on the server of each provincial center and applied for the managements of testing spot, tester, test task, test result, result analysis, etc.,. 
Figure 5 below shows the operation interface of voice testing, and Figure 6 shows the main operation interface of words test and voice collection.

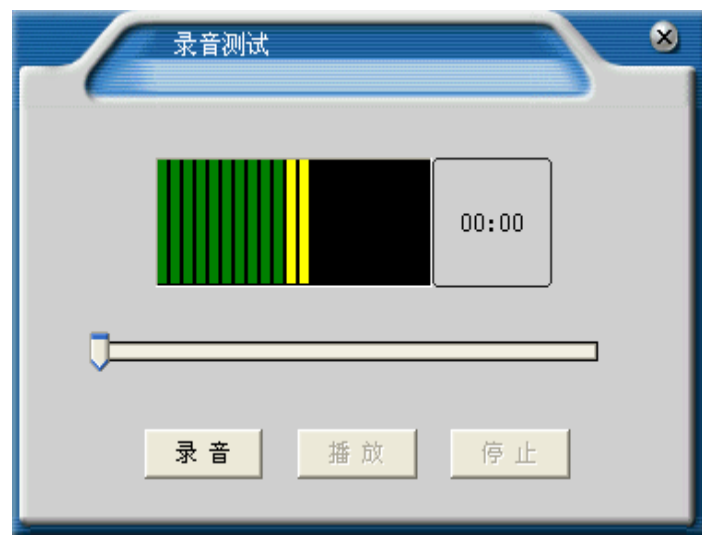

Figure 5. The Interface of Recording Detecting

\subsection{Application Analysis}

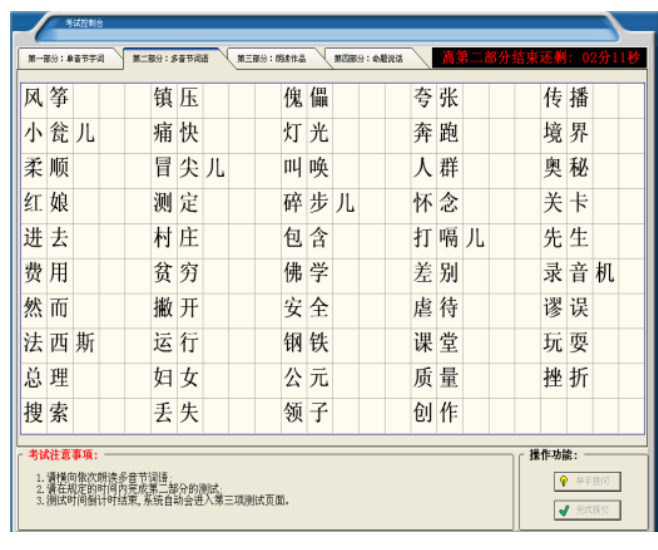

Figure 6. The Interface of Words Test

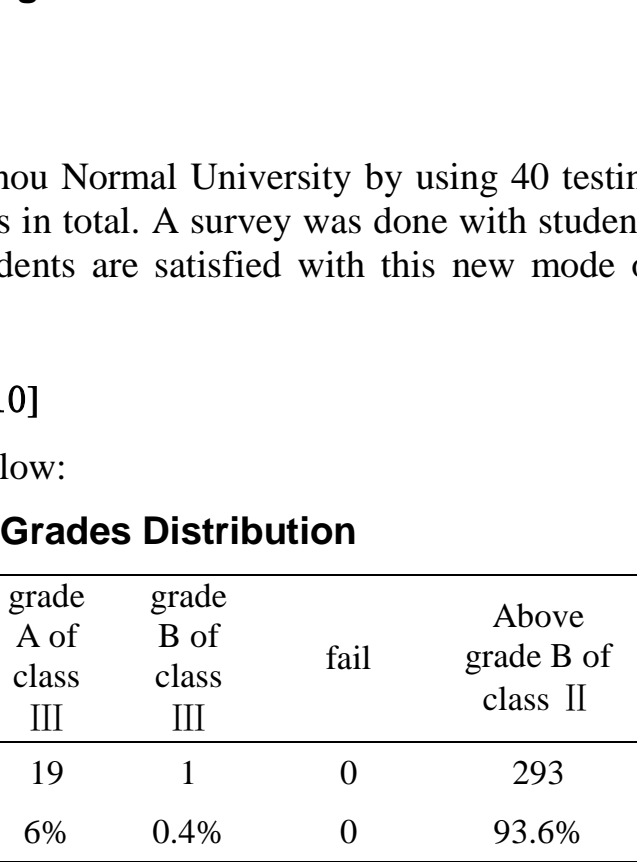

The test is performed by 313 people in Hangzhou Normal University by using 40 testing terminals; it took 15 minutes for each with 2 hours in total. A survey was done with students after this test, and it shows that most of the sludents are satisfied with this new mode of testing.

\subsubsection{The Effects and Passing Rate of the Test [10]}

The result of this test is shown in the Table 1 below:

Table 1.Statistics of Test Grades Distribution

\begin{tabular}{|c|c|c|c|c|c|c|}
\hline items & $\begin{array}{l}\text { grade } \\
\text { fof }\end{array}$ & $\begin{array}{l}\text { grade } \\
\text { B of } \\
\text { class } \\
\text { II }\end{array}$ & $\begin{array}{c}\text { grade } \\
\text { A of } \\
\text { class } \\
\text { III }\end{array}$ & $\begin{array}{c}\text { grade } \\
\text { B of } \\
\text { class } \\
\text { III }\end{array}$ & fail & $\begin{array}{l}\text { Above } \\
\text { grade B of } \\
\text { class II }\end{array}$ \\
\hline number & 100 & 192 & 19 & 1 & 0 & 293 \\
\hline ratio & $31.9 \%$ & $61.4 \%$ & $6 \%$ & $0.4 \%$ & 0 & $93.6 \%$ \\
\hline
\end{tabular}

According to the statistics on the distribution of college students' mandarin scores over years by Zhejiang province mandarin training and testing center, grade $b$ of class $I I$ and above is mithin $89 \%-95 \%$ generally, so this test pass rates of grade b of class $I$ and above is in normal range, the distribution of scores is a nearly normal fashion.

\subsubsection{Comparative Analysis of Test Management}

According to this test, the advantages of network testing mode are obvious in terms of management as Figure 2 shows: 
Table 2. Comparison and Analysis on Management Model

\begin{tabular}{|c|c|c|}
\hline & Traditional face-to-face test mode & Remote test mode \\
\hline $\begin{array}{c}\text { test } \\
\text { organization }\end{array}$ & $\begin{array}{l}11 \text { test rooms needed, testers are at the } \\
\text { scene, whose accommodation and } \\
\text { food supply problems must be } \\
\text { concerned }\end{array}$ & $\begin{array}{l}\text { test rooms are appointed, testers need not } \\
\text { to be oragnized at the same tiem, which is } \\
\text { a qualitative change }\end{array}$ \\
\hline test time & one day, about 10 hours & $\begin{array}{l}40 \text { people per batch , } 15 \text { minutes for each } \\
\text { batch, } 2 \text { hours in total. }\end{array}$ \\
\hline $\begin{array}{c}\text { tester } \\
\text { arrangement }\end{array}$ & $\begin{array}{l}22 \text { testers have to be organized in } \\
\text { advance, who will get to test rooms at } \\
\text { the appointed time }\end{array}$ & $\begin{array}{l}\text { arranged according to the test tasks, } \\
\text { testers do remote grading according to } \\
\text { their own time and place }\end{array}$ \\
\hline $\begin{array}{c}\text { test } \\
\text { management }\end{array}$ & $\begin{array}{l}\text { a day's work, always arranged in the } \\
\text { two-day weekend }\end{array}$ & $\begin{array}{l}\text { test cycle is arranged according to the } \\
\text { center's plan, testing process is monitored } \\
\text { by remote test and grading management } \\
\text { plateform }\end{array}$ \\
\hline test cost & $7320 \mathrm{RMB}$ & $4300 \mathrm{RMB}$ \\
\hline $\begin{array}{c}\text { overall } \\
\text { evaluation }\end{array}$ & Inefficient & \\
\hline
\end{tabular}

Now, The research findings have been applied to mandarin Chinese test. So far Over 10 organization users have adopted the system and more than 300,000 examinees have been tested. Viewed from the practice, expected effects have been acheved.

\section{Conclusions}

Under the background of the deepening educational imformatization, faced with the problems that exist in traditional oral examinations, the information-based reform of oral examinations must be enforced. The papen brings forward the computer assisted oral examinations and management models, strives to integrate the computer assisted examination system into the entire teaching process seamlessly for standardizing the management and promoting the teaching, and designs a universal system framework of oral examinations. Henceforth, we will probe into the areas of applying this universal framework to the mandarin proficiency test, oral English test and so on, intensive study the speech recognition and evaluation techmique, to develop a fully intelligent type of oral examination system.

\section{References}

[1]. C. Lei, H. Kit-Tai, H. Wai-Kit and W. Jian-Bin, "Putonghua test: feasibility of tape-recorded marking, reliability and economic efficiency", Acta psychologica sinica, vol. 33, no. 2, (2001), pp. 97-103.

[2]. Z. Pu-Rong, "On the Problems with Proficiency Test of Mandarin in Zhejiang Province", Journal of ningbo uniyersity (education edition), (2009), pp. 08.

[3] D. M. Kenyon, "Malabonga Comparing example attitudes toward computer-assised and other oral rofieieney assessment", Language learning and technology, (2001), pp. 5.

[4]. C A. Chapelle and Y.-R. Chung, "The promise of NLP and speech processing technologies in language assessment”, Language Testing, (2010) July 27, pp. 301-315.

[5]. M. Chodorow, M. Gamon and J. Tetreault, "The utility of article and preposition error correction systems for English language learners: Feedback and assessment", Language Testing, (2010) July 27, pp. 419-436.

[6]. Y. Jin, "The place of language testing and assessment in the professional preparation of foreign language teachers in China", Language Testing, (2010) October 27, pp. 555-584.

[7]. "The State Language Work Committee Putonghua test training center", Implementation Outline for Putonghua Proficiency Test, Beijing: Commercial Press, (2004).

[8]. L. Caorong, "Design and implementation of computer-assisted test system", Guangdong University of Technology, (2007). 
[9]. L. Xin, "Design and implementation of an object oriented computer-assisted test system", Northeastern University, (2007).

[10]. "Mandarin Training and Testing Center", Zhejiang Province, The summary report of national mandarin proficiency test management system, (2009).

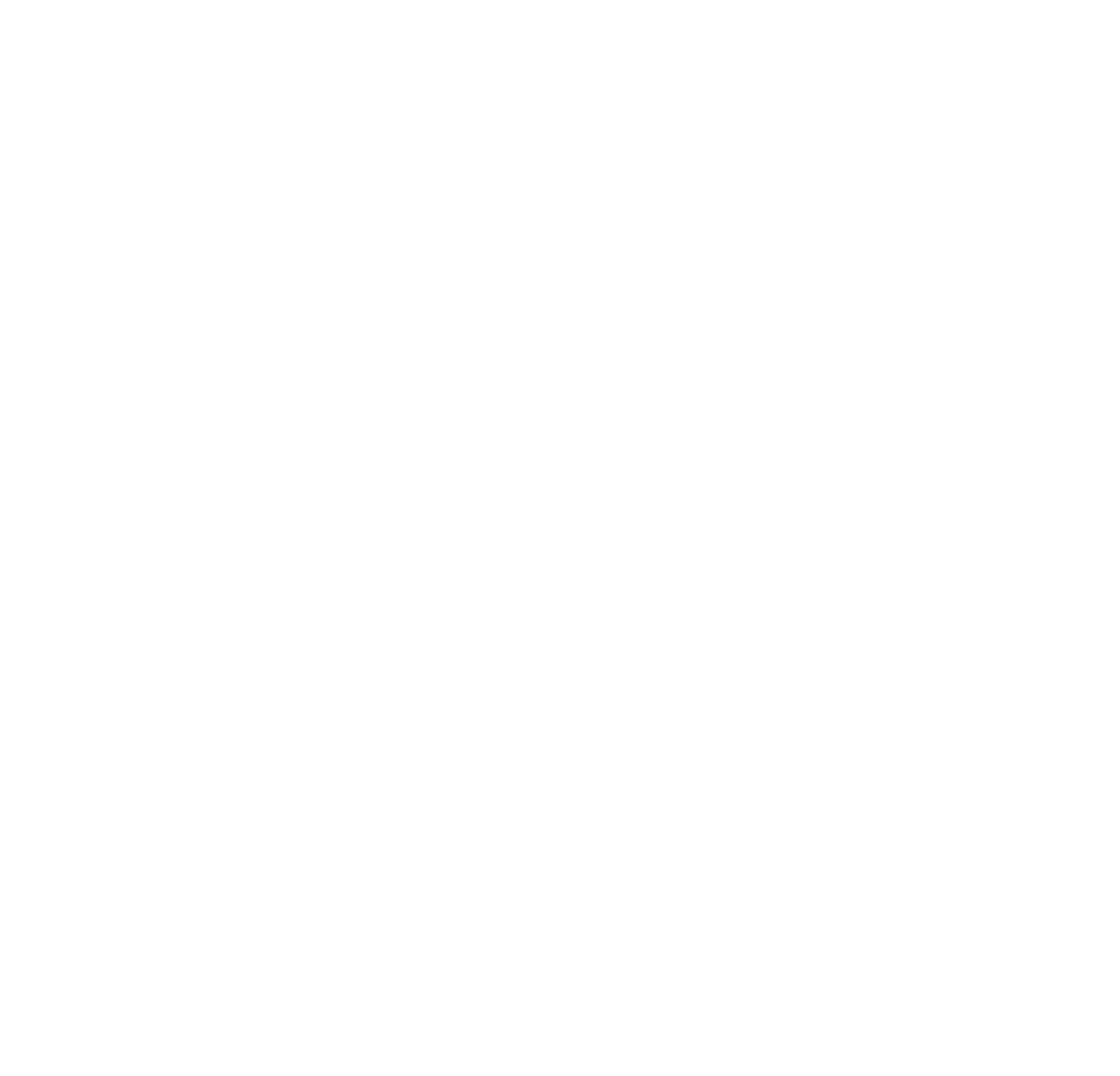


International Journal of Multimedia and Ubiquitous Engineering Vol. 9, No. 12 (2014)

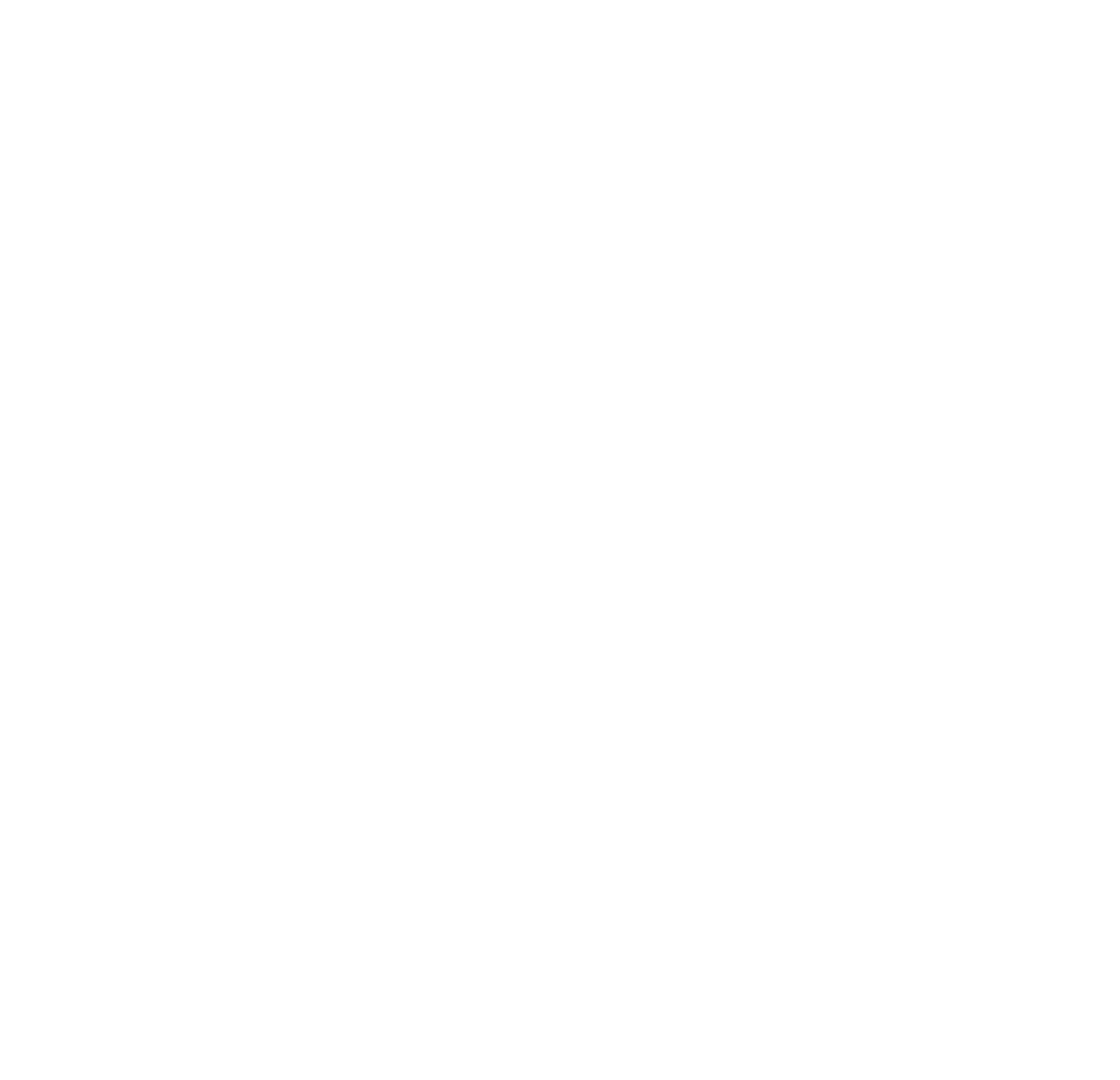

